\title{
Consumption of Drugs and Nonpharmacological Therapies in Caregivers of Patients with Alzheimer's Disease: A Case-Control Study in Madrid
}

\author{
Raquel Martín-García ${ }^{a} \quad$ Guillermo Martín-Avila ${ }^{a}$ \\ María De la Rubia-Marcos ${ }^{a}$ Raquel Maroto-Rodríguez ${ }^{a}$ \\ Celia Ortega-Angulo ${ }^{a}$ María Teresa Carreras Rodriguez ${ }^{b}$ \\ Francisco Abad Santos ${ }^{c}$ Ana Beatriz Gago Veiga ${ }^{b}$

\begin{abstract}
a Universidad Autónoma de Madrid, ${ }^{b}$ Alzheimer's Disease and Other Cognitive Disorders Unit, Department of Neurology, Hospital Universitario de la Princesa, Instituto de Investigación Sanitaria Princesa (IP), and ${ }^{\mathrm{C} C l i n i c a l ~ P h a r m a c o l o g y ~ S e r v i c e, ~ H o s p i t a l ~}$ Universitario de la Princesa, Instituto Teófilo Hernando, Instituto de Investigación Sanitaria Princesa (IP), Madrid, Spain
\end{abstract}

\section{Key Words}

Burden · Caregivers · Dementia $\cdot$ Treatment

\begin{abstract}
Background: Dementia is a neurodegenerative disease whose prevalence is rising, and the need for assistance to patients becomes indispensable. The different types of dementia and their treatments have been widely studied; however, the health status of caregivers also requires our attention. Objective: The aim of our research was to evaluate whether caregivers of patients with dementia consume more medications than the general population, indicating underlying pathologies. Methods: A total of 91 caregivers of dementia patients were interviewed and their answers were compared with those from a control group of 48 people, taking into account demographic data, characteristics of patients and caregivers, pharmacological and nonpharmacological treatments and burden. Results: Caregivers showed a significantly higher consumption of anxiolytics, antidepressants and antiplatelets $(22.3,13.2$ and $11 \%$, respectively) than the control group (14.6, 0 and $0 \%$, respectively). Moreover, $45.1 \%$ of the caregivers used nonpharmacological therapies compared with $6.2 \%$ of the control
\end{abstract}

R.M.-G., G.M.-Á., M.d.I.R.-M., R.M.-R. and C.O.-A. contributed equally to this study. 
group. There was a tendency to take more medications in those caregivers suffering from burden and those who had to take care of patients with behavioral changes. Conclusion: Caregivers of dementia patients need more pharmacological and nonpharmacological therapies. They are a risk group that needs better care from the health system.

(C) 2016 The Author(s)

Published by S. Karger AG, Basel

\section{Introduction}

The prevalence of diseases associated with age, such as dementia, is rapidly increasing because of the population ageing. Between 25 and 30\% of those who are 85 years and older have some degree of cognitive impairment. In Spain, the prevalence of this disease is estimated to be higher than 600,000 people [1].

Due to the degenerative nature of dementia, alterations in cognitive, functional and social spheres gradually occur, generating an increasing dependence, which results in the need for a caregiver's intervention. For our project, we defined 'caregiver' as a family member responsible for the care of others, without receiving any compensation. In the USA, more than 15 million family members, friends and neighbors provided care without payment to Alzheimer's disease patients in 2014 [2]. The constant support and dedication that carers provide to patients with dementia seriously affects their own quality of life [3].

Because of that impact, one of the first manifestations is evident in the psychological state of the caregiver, including frequent stress, as shown in several articles [4, 5]. In fact, providing care to patients with Alzheimer's disease is a common model for studying stress impact [6]. Due to this high stress level, these family caregivers are at a higher risk of becoming physically or mentally diseased [7], leading, in a considerable number of occasions, to a state of depression, as reported by several studies [5, 6, 8-13].

But it is not only the psychological aspect which is altered, because, as several studies have been commissioned to demonstrate, the condition of caregivers of dementia patients is associated with an increased incidence of psychosomatic effects, such as increased cardiovascular risk [14-18], coagulation problems [15, 19], chronic stress [20], sleep problems [19,21] and decreased immune function, leading to increased risk of infection (primarily of the upper respiratory tract) and recovery time thereof [22-24].

So, it is clear that caregivers of patients with dementia are highly physically and mentally burdened, being this burden higher than that felt by other caregivers [7]. Furthermore, this burden leads to acute and chronic illness, making caregivers just as ill as the person whom they are taking care of $[25,26]$. For all these reasons, the caregiver status has been linked to an increased risk of death [19, 20, 27-29].

The aim of this study was to assess whether caregivers of dementia patients consume more drugs than the general population, indicating underlying pathologies these caregivers might be suffering.

\section{Materials and Methods}

\section{Study Design and Participants}

This is a cross-sectional study that was carried out in Madrid from February to August 2013 based on an oral survey directed to a group of cases and controls. A sample of 91 cases was selected based on the following inclusion criteria: taking care of a family member diagnosed with dementia, not receiving remuneration for it and being the primary caregiver. 
Table 1. Demographic data (average \pm standard deviation or percentage)

\begin{tabular}{lll}
\hline Features & Cases $(\mathrm{n}=91)$ & Controls $(\mathrm{n}=48)$ \\
\hline $\begin{array}{l}\text { Age, years } \\
\text { Sex }\end{array}$ & $67.96 \pm 12.61$ & $66.45 \pm 14.01$ \\
$\quad$ Men & $36(39.56 \%)$ & $19(39.58 \%)$ \\
$\quad$ Women & $55(60.43 \%)$ & $29(60.42 \%)$ \\
Spanish nationality & $90(98.90 \%)$ & $48(100 \%)$ \\
Higher education & $36(39.6 \%)$ & $13(27.1 \%)$ \\
\hline
\end{tabular}

Case finding was conducted in the waiting room of the Memory Unit of the Neurology Service at the Hospital Universitario La Princesa, in the Elderly Day Centre 'El Bosque' in Madrid and among members of the association of relatives of patients with Alzheimer disease of Parla (Madrid). As a reference, a group of 48 controls was chosen randomly within the Madrid population, specifically among medicine students' relatives and people who were accompanying patients without dementia to the Hospital Universitario La Princesa. These controls had to meet the following requirements: same sex as the corresponding case and within an age range of \pm 5 years ( 1 control for every 2 cases), not having a first-degree relative (father, mother, siblings and children) with dementia, not taking care of ill people and not being cared for by anyone. As no previous data were available, we did a pilot study and no formal sample size calculation was performed.

\section{Determining Variables}

The variables analyzed in the study were collected in a single interview under the same conditions for both the cases and controls. This survey included demographics data, such as age, sex, nationality and educational level as well as information about their caregiving role and information related to the possible pathologies suffered by participants and drug use for their treatment.

Caregivers were also asked about how long they had been taking care of the patient and the time dedicated per day, kinship, if they were in charge of someone else, if they had a job, if they received external help (home assistant, other family member, etc.), as well as whether they had received any informative session about the disease and its care. In addition, the survey included some questions about the patient, such as age, the duration of time the patient has been suffering from dementia and whether the patient had behavioral problems (based on the caregiver's interview), divided into positive (irritability, restlessness and/or aggression) and negative symptoms (apathy and/or sadness). Finally, the respondents were asked if they received some kind of nonpharmacological support (psychologist, therapist, social worker, support of an association of relatives of patients, etc.) and whether they felt burdened (data obtained from the clinic interview with the caregiver).

The information about behavioral changes in patients could not be evaluated for every participant because of modifications that took place during the process of our study. These modifications were made to improve the quality of our project, based on the relevance of information, according to the literature [7].

\section{Statistical Analysis}

Survey data were tabulated using Microsoft Excel, which served for descriptive statistics. The quantitative variables are presented as average and standard deviation and qualitative variables are given as percentages. The comparison between cases and controls was performed with the $\chi^{2}$ test. SPSS 22.0 was used, and results were considered statistically significant when $\mathrm{p}<0.05$. 
Martín-García et al.: Consumption of Drugs and Nonpharmacological Therapies in Caregivers of Patients with Alzheimer's Disease: A Case-Control Study in Madrid

Table 2. Number (and percentage) of cases and controls receiving drugs from each of the drug groups

\begin{tabular}{llcl}
\hline Pharmacological group & Cases $(\mathrm{n}=91)$ & Controls $(\mathrm{n}=48)$ & $\mathrm{p}$ \\
\hline Analgesics & $20(22.2 \%)$ & $7(14.6 \%)$ & 0.281 \\
Antihypertensive & $37(40.7 \%)$ & $20(41.7 \%)$ & 0.376 \\
Cholesterol-lowering drugs & $23(25.3 \%)$ & $1(2.1 \%)$ & 0.385 \\
Anxiolytics & $22(24.2 \%)$ & 0 & 0.001 \\
Antidepressants & $12(13.2 \%)$ & $5(10.4 \%)$ & 0.008 \\
Osteoporosis medication & $8(8.8 \%)$ & $12(25.0 \%)$ & 0.754 \\
Gastroprotectives & $17(18.7 \%)$ & 0 & 0.249 \\
Antiplatelets & $10(11.0 \%)$ & $2(4.2 \%)$ & 0.017 \\
Thyroid hormone & $4(4.4 \%)$ & $6(12.5 \%)$ & 0.950 \\
Anti-COPD & $5(5.5 \%)$ & $7(14.6 \%)$ & 0.146 \\
Antidiabetics & $9(9.9 \%)$ & $6(12.5 \%)$ & 0.410 \\
Prostate drugs & $4(4.4 \%)$ & $10(20.8 \%)$ & 0.950 \\
Anticoagulants & $4(4.4 \%)$ & $($ antiarrhythmics, hypouricemics, \\
Others & $20(22 \%)$ & laxatives, oral contraceptives, \\
& $($ eyedrops, eardrops, antiarrhythmics, & 0.079 \\
\hline antiepileptics, antihistamines, & antipsoriatics, antiepileptics, cataracts \\
\hline & magnesium, vitamin B and D, & medications and prostate cancer \\
\hline
\end{tabular}

\section{Ethical Aspects}

All interviewees were thoroughly explained the project and indicated that they volunteer in participating. If they agreed to collaborate, the questionnaire was administered anonymously, maintaining data confidentiality at any time and without collecting identification data, so no written consent was requested.

The project was approved by the Ethics Committee for Clinical Research of the Hospital Universitario La Princesa.

\section{Results}

Numerical values for age and sex in cases and controls are similar according to the selection criteria (table 1). The participants have an age of around 67-68 years and there is a higher percentage of women (60.43\%). Most cases (98.90\%) and all controls (100\%) have Spanish nationality, and 39.6 and $27.1 \%$, respectively, have a higher education.

An important aspect in studying the characteristics of caregivers and patients with dementia is the time spent taking care of the diseased relative (averaging $5.06 \pm 3.87$ years). The kinship of the caregiver was also asked, and we found a higher percentage of wives (33\%) and husbands (33\%), followed by sons and daughters $(26.4 \%)$. Other minority groups are: nephew/niece $(3.3 \%)$, sister-in-law (2.2\%) and sister/brother (2.2\%). Most caregivers $(83.5 \%)$ reported to spend more than $20 \mathrm{~h}$ a week caring for the patient; they did not have anyone else in charge (85.7\%) and they did not work (72.5\%), but only 3.3\% stopped working to care for the patient [19 $(20.9 \%)$ participants did not answer this last question]. The remaining group of caregivers spent between 7 and $20 \mathrm{~h}(8.8 \%)$ or less than $7 \mathrm{~h}(6.6 \%)$ per week taking care of the patient [ 1 (1.1\%) person did not answer this question]. Less than $40 \%$ of the cases $(38.5 \%)$ received an informative session about the disease and its care [unanswered: $2(2.2 \%)]$. 
Martín-García et al.: Consumption of Drugs and Nonpharmacological Therapies in Caregivers of Patients with Alzheimer's Disease: A Case-Control Study in Madrid

Table 3. Number (and percentage) of cases and controls receiving nonpharmacological treatments

\begin{tabular}{lcll}
\hline & Cases $(\mathrm{n}=91)$ & Controls $(\mathrm{n}=48)$ & $\mathrm{p}$ \\
\hline Psychologist & $16(17.6 \%)$ & 0 & 0.004 \\
Physiotherapist & $6(6.6 \%)$ & $2(4.2 \%)$ & 0.485 \\
Social worker & $15(16.5 \%)$ & $1(2.1 \%)$ & 0.021 \\
Support of an association & $26(28.6 \%)$ & 0 & 0.000 \\
Others & $1(1.1 \%)$ & 0 & 0.466 \\
None & $49(53.8 \%)$ & $45(93.8 \%)$ & 0.000 \\
No answer & $1(1.1 \%)$ & 0 & 1.000 \\
\hline
\end{tabular}

Table 4. Relationship between subjective burden and consumption of analgesics, anxiolytics, antidepressants and antiplatelets in cases

\begin{tabular}{lclll}
\hline \multirow{2}{*}{ Drugs } & \multicolumn{2}{l}{ Burden } & & \\
\cline { 2 - 5 } & yes $(\mathrm{n}=61)$ & no $(\mathrm{n}=21)$ & no answer $(\mathrm{n}=9)$ & $\mathrm{p}$ \\
\hline Analgesics & $14(23.3 \%)$ & $4(19.0 \%)$ & $2(22.2 \%)$ & 0.921 \\
Anxiolytics & $19(31.1 \%)$ & $1(4.8 \%)$ & $2(22.2 \%)$ & 0.05 \\
Antidepressants & $9(14.8 \%)$ & $2(9.5 \%)$ & $1(11.1 \%)$ & 0.814 \\
Antiplatelets & $6(9.8 \%)$ & $3(14.3 \%)$ & $1(11.1 \%)$ & 0.854 \\
\hline
\end{tabular}

External support was considered an important aspect in the process of caring, but $21.97 \%$ did not receive it, and $1(1.1 \%)$ person did not answer this question. The most frequent support came from day centers (35.2\%), other family members $(27.47 \%)$, home assistants $(21.97 \%)$ and associations of relatives of patients $(16.9 \%)$. The average patient age was around $78.32 \pm 7.48$ years, with an average duration of suffering from the disease of $4.76 \pm$ 3.20 years. The behavioral symptoms were only evaluated in 61 cases; of those, $57.38 \%$ of the cared patients reported positive symptoms (irritability, restlessness and/or aggression), $19.67 \%$ reported negative symptoms (apathy and/or sadness) and 14.75\% reported both, while 30 cases did not answer this question.

More than $80 \%$ of cases and controls take some drug (table 2). Consumption of anxiolytics, antidepressants and antiplatelets was higher in the case group $(24.2,13.2$ and $11 \%$, respectively) than in the controls $(2.1,0$ and $0 \%$, respectively). The nonpharmacological treatments of the case and control groups are represented in table 3 . Less than $7 \%$ of the controls require this kind of therapies, compared with around half of the cases. It was also found that nearly $30 \%$ of the cases were supported by an association.

We also studied the feeling of burden; although only 82 cases and 38 controls answered this question, 61 cases $(67 \%)$ responded affirmatively versus none of the controls $(p<0.001)$. There was a trend towards a higher percentage of use of analgesics, antidepressants and anxiolytics among the cases that felt burdened (23.3\% took analgesics and $31.1 \%$ anxiolytics) compared to the nonburdened cases (19\% used analgesics and $4.8 \%$ anxiolytics), but statistical significance was only reached for anxiolytics (table 4). Caregivers of patients with positive symptoms for the behavioral changes used more analgesics, antidepressants and anxiolytics (only significant for anxiolytics), but less antiplatelets (table 5).

If we relate the consumption of drugs with receiving no assistance from associations or psychologists, we can find a few interesting differences. For example, there is a notably higher consumption of anxiolytics ( 23.1 vs. $25.4 \%$ ), analgesics (30.8 vs. $17.7 \%$ ), antihypertensives (50 vs. $34.9 \%$ ) and statins (36.4 vs. $22.2 \%$ ) among those seeking help from associations/ 
Table 5. Relationship between behavioral changes and consumption of different treatments

\begin{tabular}{|c|c|c|c|c|c|c|}
\hline \multirow[t]{2}{*}{ Drugs } & \multicolumn{6}{|l|}{$\begin{array}{l}\text { Behavioral } \\
\text { changes }\end{array}$} \\
\hline & $\begin{array}{l}\text { positive } \\
\text { symptoms } \\
(\mathrm{n}=44)\end{array}$ & $\begin{array}{l}\text { negative } \\
\text { symptoms } \\
(\mathrm{n}=21)\end{array}$ & $\begin{array}{l}\text { positive and } \\
\text { negative } \\
\text { symptoms } \\
(\mathrm{n}=9)\end{array}$ & $\begin{array}{l}\text { total with } \\
\text { behavioral } \\
\text { changes } \\
(n=56)\end{array}$ & $\begin{array}{l}\text { without any } \\
\text { behavioral } \\
\text { changes } \\
(n=5)\end{array}$ & $\begin{array}{l}\text { p (total } \\
\text { behavioral } \\
\text { change vs. no } \\
\text { change) }\end{array}$ \\
\hline Analgesics & $12(27.3 \%)$ & $4(20 \%)$ & $2(22.2 \%)$ & $14(25.5 \%)$ & $6(17.1 \%)$ & 0.355 \\
\hline Anxiolytics & $17(38.6 \%)$ & $6(28.6 \%)$ & $4(44.4 \%)$ & $19(33.9 \%)$ & $3(8.6 \%)$ & 0.006 \\
\hline Antidepressants & $8(18.2 \%)$ & $4(19.0 \%)$ & $2(22.2 \%)$ & $10(17.9 \%)$ & $2(5.7 \%)$ & 0.096 \\
\hline Antiplatelets & $3(6.8 \%)$ & 0 & 0 & $3(5.4 \%)$ & $7(20.0 \%)$ & 0.03 \\
\hline
\end{tabular}

psychologists compared with those who do not. By contrast, more cases receiving no support from associations did not take any drug (22.2 vs. 15.38\%).

Wealso analyzed the relationship between some demographic data and drug consumption, i.e. between the gender of caregivers and four groups of drugs (analgesics, anxiolytics, antidepressants and antiplatelets), usually getting higher percentages among female caregivers, except for antiplatelets (female vs. male: 24.1 vs. $19.4 \%, 36.4$ vs. $5.6 \%, 16.4$ vs. $8.3 \%$ and 7.3 vs. $16.7 \%$, respectively). Anxiolytics are the only group of drugs that achieved a statistically significant difference.

By analyzing the relationship between the same groups of drugs and having or not a higher education, we noticed that only analgesics and anxiolytics achieved a significant difference, i.e. a higher consumption among caregivers with a higher education (8.3 vs. 30.9\% and 8.3 vs. $34.5 \%$, respectively).

\section{Discussion}

Our results show that there are statistically significant differences in the consumption of antidepressants, anxiolytics and antiplatelets among caregivers of patients with dementia and noncaregivers. Considering the study of the consumption of antidepressants and anxiolytics, two authors have succeeded in demonstrating an association between this consumption and caregiving [30, 31]. Clipp and George [30] compared the use of psychotropic drugs in a group of caregivers with the prevalence of consumption in the general population showing a significant difference. Camargos et al. [31] found that the caregivers of patients with dementia consumed more benzodiazepines, antidepressants and psychotropic drugs than caregivers of patients without dementia.

It is notable that the use of these drugs is higher in our study than in previous ones. The reason could be because most of the interviews with caregivers were carried out in a hospital environment, increasing the probability of an advanced stage of dementia.

In our study, the comparison was made with a control group which was similar regarding age and sex, and, unlike the two studies mentioned above, we did not only focus on the association of psychotropic drugs but also analyzed all kinds of drugs, demonstrating, among others, a statistically significant association between antiplatelet drugs and caring for patients with dementia. This association may probably be related to an increased cardiovascular risk in this group; however, we were unable to demonstrate this. 
As previous literature shows that there is an increased risk of physical illness in caregivers of patients with dementia, we consider it essential to extend the search for drugs that can be related to caregivers [16, 32]. Delgado Parada et al. [32] conducted a study which found that primary caregivers of patients with dementia use more antidepressants and anxiolytics than the general population. Van Houten et al. [33], on the other hand, only linked the consumption of psychotropic drugs with the number of hours dedicated to a patient, but not with the burden. However, the work of Roepke et al. [16] demonstrates an association between cholesterol-lowering drugs and the status of caregivers of patients with dementia. In our case, although we could not detect statistical significance, we did find a positive trend towards the use of cholesterol-lowering drugs and the condition of caregivers because, as it has been shown, being a caregiver is related to endocrine-metabolic disturbances and an increased likelihood of having metabolic syndrome [20].

We have also shown that there is a higher percentage of caregivers receiving nonpharmacological treatment compared to noncaregivers. Various therapies have proven to be effective in reducing the burden of caregivers [3, 34,35], the group therapies and specifically the cognitive behavioral therapy being most effective [24,36,37]. In our case, $28.6 \%$ of the caregivers went to an association that offered a group therapy similar to cognitive behavioral therapy, $17.6 \%$ went to a psychologist and $16.5 \%$ received help from a social worker. In this regard, we have found that caregivers who use nonpharmacological support (associations and psychologists) take more anxiolytics, analgesics, antihypertensives and statins than those who do not use these aids, although statistical significance was not reached. This could be the result of the duration of time they have been on therapy and the fact that it is precisely the most burdened caregivers who come to the association. Group therapies have proven effective in the long term, and probably after months or years of therapy, caregivers will use less drugs, especially anxiolytics.

We can also see that there is a significant difference between the number of individuals in the group of caregivers who are subjectively burdened and the control group, as other projects had also indicated before [38, 39]. Increased burden has been linked to factors such as female sex, ageing, higher educational level, being institutionalized, the behavior of patients they care for, whether or not they have any geriatric syndrome (particularly urinary incontinence), dependence in basic and instrumental activities for daily living, the degree of cognitive impairment of the patient, appraisal and social support [9, 16, 19, 21, 35, 40-42]. Although our study did not focus on finding a relationship between burden and demographic variables, our caregiver profile (a burdened wife of 67-68 years of age with a low educational level and no job) corresponds largely to the standard caregiver profile shown by other authors [4, 32, $43,44]$ that associates these variables with a greater degree of burden [45-48]. Some studies talk about the effect of culture [49] and religion [50,51] on caregivers, but we did not analyze these data, since $98.90 \%$ of our caregivers were Spanish and their religion, due to privacy reasons, was not requested.

In our study, the degree of burden has been linked to drug consumption, finding statistically significant differences in the consumption of anxiolytics. This relationship has already been demonstrated by Pérodeau et al. [52] and Delgado Parada et al. [32]. Pérodeau et al. [52] studied mental health and stress in patients who use psychotropics and those who do not, and they concluded that those who consumed psychotropics had a worse mental health and were under more stress. Meanwhile, Delgado Parada et al. [32] linked analgesic consumption with the degree of the caregiver's burden. However, despite finding differences in the consumption of these drugs between burdened and nonburdened caregivers, we have failed to find statistical significance. Furthermore, behavioral changes have been linked to a higher level of burden [53-58]. We have managed to find a trend between these changes and the analgesic 
consumption in caregivers. Therefore, behavioral disturbances can be related not only to an increase in the caregiver's burden, but also to an increased use of drugs by them.

The small sample size is the main limitation of our study; it would be desirable to conduct new studies with a larger sample size in order to obtain greater statistical power. Unlike in the study by Clipp and George [30], we did not take into account the number of times the caregivers go to a doctor as a parameter to assess their health. Finally, we should be aware that our study is subject to nonresponse bias.

In conclusion, this study indicates that the use of drugs in general is an objective marker that shows the negative effects, in terms of a physical and psychological burden, of caring for patients with dementia. Due to the increasing prevalence of dementia in the population, it is important that the health system considers this issue, so it could take action to prevent that the caregivers become themselves patients. Other solutions, like cognitive behavioral therapies or caregivers' training courses, could reduce the use of psychotropic drugs in both the demented patients and caregivers, and should therefore be taken into account.

\section{Acknowledgments}

This work would not have been possible without the collaboration of the Association of Relatives of Patients with Alzheimer of Parla (AFA Parla). Thanks to its director Lucia Jimenez and Tania Rodríguez Fernández, psychologist and connecting link between the caregivers and us. Thanks also to Rebeca Sainz, social worker in the Elderly Day Centre 'El Bosque', in Madrid, for her help and the interest shown in our project. And last but not least, thanks to Ángela for her great correction work.

\section{References}

1 De Pedro-Cuesta J, Virués-Ortega J, Vega S, Seijo-Martínez M, Saz P, Rodríguez F, Rodríguez-Laso A, Reñé R, de las Heras SP, Mateos R, Martínez-Martín P, Manubens JM, Mahillo-Fernandez I, López-Pousa S, Lobo A, Reglà JL, Gascón J, García FJ, Fernández-Martínez M, Boix R, Bermejo-Pareja F, Bergareche A, Benito-León J, de Arce A, del Barrio JL: Prevalence of dementia and major dementia subtypes in Spanish population: a reanalysis of dementia prevalence surveys, 1990-2008. BMC Neurol 2009;9:55.

2 Alzheimer's Association: Alzheimer's disease facts and figures. Alzheimers Dement 2014;10:47-92.

-3 Lykens K, Moayad N, Biswas S, Reyes-Ortiz C, Singh KP: Impact of a community based implementation of REACH II program for caregivers of Alzheimer's patients. PLoS One 2014; 9:e89290.

4 Brodaty H, Green A, Koschera A: Meta-analysis of psychosocial interventions for caregivers of people with dementia. J Am Geriatr Soc 2003;51:657-664.

5 Ferrara M, Langiano E, Di Brango T, De Vito E, Di Cioccio L, Bauco C: Prevalence of stress, anxiety and depression in with Alzheimer caregivers. Health Qual Life Outcomes 2008;6:93.

-6 Mausbach BT, Dimsdale JE, Ziegler MG, Mills PJ, Ancoli-Israel S, Patterson TL, Grant I: Depressive symptoms predict norepinephrine response to a psychological stressor task in Alzheimer's caregivers. Psychosom Med 2005;67:638-642.

7 Pinquart M, Sorensen S: Associations of caregiver stressors and uplifts with subjective well-being and depressive mood: a meta-analysis. Aging Ment Health 2004;8:438-449.

8 Aneshensel C, Pearlin LI, Mullan JT, Zarit SH, Whitlach CJ: Profiles in Caregiving: The Unexpected Career. San Diego, Academic Press, 1995.

\$ Clyburn LD, Stones MJ, Hadjistavropoulos T, Tuokko H: Predicting caregiver burden and depression in Alzheimer's disease. J Gerontol B Psychol Sci Soc Sci 2000;55:S2-S13.

10 Gnaedinger N: The Alzheimer's household: who cares for the caregivers? CMAJ 1989;141:1273-1275.

11 Epstein-Lubow G, Gaudiano B, Darling E, Hinckley M, Tremont G, Kohn R, Marino Louis J, Salloway S, Grinnell $\mathrm{R}$, Miller Ivan W: Differences in depression severity in family caregivers of hospitalized individuals with dementia and family caregivers of outpatients with dementia. Am J Geriatr Psychiatry 2012;20:815-819.

$\checkmark 12$ Vitaliano PP, Zhang J, Young HM, Caswell LW, Scanlan JM, Echeverria D: Depressed mood mediates decline in cognitive processing speed in caregivers. Gerontologist 2009;49:12-22. 
13 Kwok T, Au A, Wong B, Ip I, Mak V, Ho F: Effectiveness of online cognitive behavioral therapy on family caregivers of people with dementia. Clin Interv Aging 2014;9:631-636.

14 Mausbach BT, Patterson TL, von Känel R, Mills PJ, Dimsdale JE, Ancoli-Israel S, Grant I: The attenuating effect of personal mastery on the relations between stress and Alzheimer caregiver health: a five-year longitudinal analysis. Aging Ment Health 2007;11:637-644.

-15 von Känel R, Mausbach BT, Ancoli-Israel S, Dimsdale JE, Mills PJ, Patterson TL, Ziegler MG, Roepke SK, Chattillion EA, Allison M, Grant I: Sleep in spousal Alzheimer caregivers: a longitudinal study with a focus on the effects of major patient transitions on sleep. SLEEP 2012;35:247-255.

16 Roepke SK, Mausbach BT, Patterson TL, von Känel R, Ancoli-Israel S, Harmell AL, Dimsdale JE, Aschbacher K, Mills PJ, Ziegler MG, Allison M, Grant I: Effects of Alzheimer caregiving on allostatic load.J Health Psychol 2011; 16:56-69.

17 Mausbach BT, Roepke SK, Ziegler MG, Milic M, von Kanel R, Dimsdale JE, Mills PJ, Patterson TL, Allison MA Ancoli-Israel S, Grant I: Association between chronic caregiving stress and impaired endothelial function in the elderly. J Am Coll Cardiol 2010;55:2599-2606.

18 von Känel R, Ancoli-Israel S, Dimsdale JE, Mills PJ, Mausbach BT, Ziegler MG, Patterson TL, Grant I: Sleep and biomarkers of atherosclerosis in elderly Alzheimer caregivers and controls. Gerontology 2010;56:41-50.

19 Mills PJ, Ancoli-Israel S, von Känel R, Mausbach BT, Aschbacher K, Patterson TL, Aschbacher K, Patterson TL, Ziegler MG, Dimsdale JE, Grant I: Effects of gender and dementia severity on Alzheimer's disease caregivers' sleep and biomarkers of coagulation and inflammation. Brain Behav Immun 2009;23:605-610.

20 Vitaliano PP, Scanlan JM, Zhang J, Savage MV, Hirsch IB, Siegler IC: A path model of chronic stress, the metabolic syndrome, and coronary heart disease. Psychosom Med 2002;64:418-435.

21 Mc Curry SM, Longsdon RG, Teri L, Vitello MV: Sleep disturbances in caregivers of persons with dementia: contributing factors and treatment implications. Sleep Med Rev 2007;11:143-153.

22 Kiecolt-Glaser JK, Dura JR, Speicher CE, Trask OJ, Glaser R: Spousal caregivers of dementia victims: longitudinal changes in immunity and health. Psychosom Med 1991;53:345-362.

23 Zverova M: Frequency of some psychosomatic symptoms in informal caregivers of Alzheimer's disease individuals. Prague's experience. Neuro Endocrinol Lett 2012;22;33:565-567.

24 Aboulafia-Brakha T, Suchecki D, Gouveia-Paulino F, Nitrini R, Ptak R: Cognitive-behavioural group therapy improves a psychophysiological marker of stress in caregivers of patients with Alzheimer's disease. Aging Ment Health 2014;18:801-808.

25 Borghi AC, de Castro VC, Silva S, Carreira L: Sobrecarga de familiares cuidadores de ancianos con la enfermedad de Alzheimer: un estudio comparativo. Rev Latino-Am Enfermagem 2013;21.

26 Seima MD, Lenardt MH: A sobrecarga do cuidador familiar de idosocom Alzheimer. Texto Contexto Enferm 2011;10:388-398.

27 Schulz R, Visintainer P, Williamson GM: Psychiatric and physical morbidity effects of caregiving. J Gerontol 1990;45:181-191.

28 Alzheimer's Association: Alzheimer's disease facts and figures. Alzheimers Dement 2009;5:234-270.

29 Schulz R, Beach SR: Caregiving as a risk factor for mortality: the Caregiver Health Effects Study. JAMA 1999; 282:2215-2219.

30 Clipp EC, George LK: Psychotropic drug use among caregivers of patients with dementia. J Am Geriatr Soc 1990;38:227-235.

-31 Camargos EF, Souza AB, Nascimento AS, Morais-E-Silva AC, Quintas JL, Louzada LL, Medeiros-Souza P: Use of psychotropic medications by caregivers of elderly patients with dementia: is this a sign of caregiver burden? Arq Neuropsiquiatr 2012;70:169-174.

-32 Delgado Parada E, Suarez Alcarez O, de Dios del Valle R, Valdespino Páez I, Sousa Ávila Y, Braña Fernández G: Características y factores relacionados con sobrecarga en una muestra de cuidadores principales de pacientes ancianos con demencia. Semergen 2014;40:57-64.

-33 Van Houten CH, Wilson MR, Clipp EC: Informal care intensity and caregiver drug utilization. Rev of Econ Househ 2005;3:415-433.

34 Robinson K, Buckwalter K, Reed D: Differences between dementia caregivers who are users and nonusers of community services. Public Health Nurs 2013;30:501-510.

- 35 Haley WE, Levine EG, Brown SL, Bartolucci AA: Stress, appraisal, coping and social support as predictors of adaptational outcome among dementia caregivers. Psychol Aging 1987;2:323-330.

-36 Aguirre E, Hoare Z, Spector A, Woods B, Hoe J, Orrell M: The effects of a Cognitive Stimulation Therapy [CST] programme for people with dementia on family caregivers' health. BMC Geriatr 2014;14:31.

37 Passoni S, Moroni L, Toraldo A, Mazza MT, Bertolotti G, Vanacore N, Bottini G: Cognitive Behavioral group intervention for Alzheimer caregivers. Alzheimer Dis Assoc Disord 2014;28:275-282.

-38 Abdollahpour I, Noroozian M, Nedjat S, Majdzadeh R: Caregiver burden and its determinants among the family members of patients with dementia in Iran. Int J Prev Med 2012;3:544-551.

-39 Taşc S, TekinsoyKartn P, Ceyhan O, Sungur G, Göris S: Living with an Alzheimer patient in Turkey. J Neurosci Nurs 2012;44:228-234.

-40 Mausbach BT, Roepke SK, Chattillion EA, Harmell AL, Moore R, Romero-Moreno R, Bowie CR, Grant I: Multiple mediators of the relations between caregiving stress and depressive symptoms. Aging Ment Health 2012;16: 27-38. 
Martín-García et al:: Consumption of Drugs and Nonpharmacological Therapies in

Caregivers of Patients with Alzheimer's Disease: A Case-Control Study in Madrid

-41 Kamiya M, Sakurai T, Ogama N, Maki Y, Toba K: Factors associated with increased caregivers' burden in several cognitive stages of Alzheimer's disease. Geriatr Gerontol Int 2014;14:45-55.

-42 von Kanel R, Mausbach BT, Dimsdale JE, Mills PJ, Patterson TL, Ancoli-Israel S, Ziegler MG, Roepke SK, Chattillion EA, Allison M, Grant I: Cardiometabolic effects in caregivers of nursing home placement and death of their spouse with Alzheimer's disease. J Am Geriatr Soc 2011;59:2037-2044.

43 Mahoney R, Regan C, Katona C, Livingston G: Anxiety and depression in family caregivers of people with Alzheimer disease: the LASER-AD study. Am J Geriatr Psychiatry 2005;13:795-801.

44 Baumgarten M, Hanely JM, Infante-Rivard C, Batista R, Becker R, Gauthier S: Health of family members caring for elderly persons with dementia. Ann Intern Med 1994;120:126-132.

45 Gallicchio L, Siddiqi N, Langenberg P, Baumgarten M: Gender differences in burden and depression among informal caregivers of demented elders in the community. Int J Geriatr Psychiatry 2002;17:154-163.

46 Vincent C, Desrosiers J, Landreville P, Demers L; BRAD group: Burden of caregivers of people with stroke: evolution and predictors. Cerebrovasc Dis 2009;27:456-464.

47 Adelman RD, Tmanova LL, Delgado D, Dion S, Lachs MS: Caregiver burden: a clinical review. JAMA 2014;311: 1052-1059.

48 Yee JL, Schults RS: Gender differences in psychiatric morbidity among family caregivers: a review and analysis. Gerontologist 2000;40:147-164.

49 Xiao LD, Wang J, He GP, De Bellis A, Verbeeck J, Kyriazopoulos H: Family caregiver challenges in dementia care in Australia and China: a critical perspective. BMC Geriatr 2014;14:6.

50 Yiengprugsawan V, Harley D, Seubsman SA, Sleigh AC: Physical and mental health among caregivers: findings from a cross-sectional study of Open University students in Thailand. BMC Public Health 2012;12:1111.

-51 Yiengprugsawan V, Seubsman S, Sleigh AC: Health, well-being, and social indicators among monks, prisoners, and other adult members of an open university cohort in Thailand. J Relig Health 2012;51:925-933.

52 Pérodeau G, Lauzon S, Lévesque L, Lachance L: Mental health, stress correlates and psychotropic drug use or non-use among aged caregivers to elders with dementia. Aging Ment Health 2001;5:225-234.

53 Meshefedjian G, McCusker J, Bellavance F, Baumgarten M: Factors associated with symptoms of depression among informal caregivers of demented elders in the community. Gerontologist 1998;32:247-253.

54 Martire LM, Hall M: Dementia caregiving: recent research on negative health effects and the efficacy of caregiver interventions. CNS Spectr 2002;7:791-796.

55 Covinsky KE, Newcomer R, Fox P, Wood J, Sands L, Dane K, Yaffe K: Patient and caregiver characteristics associated with depression in caregivers of patients with dementia. J Gen Intern Med 2003;18:1006-1014.

-56 Gitlin LN, Belle SH, Burgio LD, Czaja SJ, Mahoney D, Gallagher-Thompson D, Burns R, Hauck WW, Zhang S, Schulz R, Ory MG; REACH Investigators: REACH Investigators. Effect of multicomponent interventions on caregiver burden and depression: the REACH multisite initiative at 6-month follow-up. Psychol Aging 2003;18: 361-374.

57 Takahashi M, Tanaka K, Miyaoka H: Depression and associated factors of informal caregivers versus professional caregivers of demented patients. Psychiatry Clin Neurosci 2005;59:473-480.

58 Joling KJ, van Hout HP, Schellevis FG, van der Horst HE, Scheltens P, Knol DL, van Marwijk HW: Incidence of depression and anxiety in the spouses of patients with dementia: a naturalistic cohort study of recorded morbidity with a 6-year follow-up. Am J Geriatr Psychiatry 2010;18:146-153. 